Research paper

\title{
An integrated approach to energy production and nutrient recovery through anaerobic digestion of Vetiveria zizanoides
}

\author{
Angelo Crocamo a , Santino Di Bernardino ${ }^{\text {b }}$, Raffaele Di Giovanni ${ }^{a}$, \\ Massimiliano Fabbricino ${ }^{\mathrm{a}, ~}{ }^{*}$, Susete Martins-Dias ${ }^{\mathrm{c}}$ \\ a University of Naples Federico II, Department of Civil, Architectural and Environmental Engineering, Via Claudio 21, 80125 Naples, Italy \\ ${ }^{\mathrm{b}}$ Laboratório Nacional de Energia e Geologia, I.P., Estrada do Paço do Lumiar, 22, 1649-038 Lisbon, Portugal

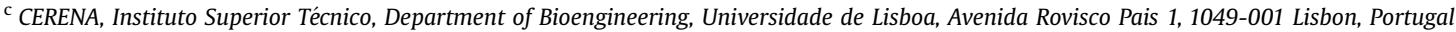

\section{A R T I C L E I N F O}

\section{Article history:}

Received 17 October 2014

Received in revised form

30 April 2015

Accepted 17 July 2015

Available online $\mathrm{xxx}$

\section{Keywords:}

Anaerobic digestion

Energy production

Nutrient recovery

Vetiveria zizanoides

\begin{abstract}
A B S T R A C T
This paper reports on experimental results used to verify the applicability of Vetiveria zizanoides (VZ) as a virtuous energetic crop. VZ produces biogas through its anaerobic digestion, and its nutrient content can be recovered through reuse, after digestion, as an agricultural amendment. Biomethanation tests were conducted with fresh and pretreated VZ, and the results of these tests were compared with those from the anaerobic degradation of common garden grass. Specific methane production was found to be around $650 \mathrm{Nm}^{3}$ per ton of total organic carbon (TOC) for Vetiveria zizanoides, and around $510 \mathrm{Nm}^{3}$ per ton of TOC for common grass, with no significant improvement after thermal pretreatment. Germination tests conducted with the digested VZ showed that the produced digestate fulfills the requirements of a fertilizer.
\end{abstract}

() 2015 Elsevier Ltd. All rights reserved.

\section{Introduction}

The anaerobic digestion of biomass is considered to be an environmentally friendly system for energy production $[1,2]$. In fact, the biogas produced by this anaerobic degradation is a renewable form of energy because biomass can be cultivated and therefore regenerated. Moreover, this energy production system does not increase greenhouse gas emissions, as the total amount of carbon dioxide directly or indirectly produced during the anaerobic degradation and successive methane burning can be assumed to be equal to the amount of $\mathrm{CO}_{2}$ subtracted from the atmosphere during the growth period of the biomass [3].

While this aspect of energy production has in general been carefully studied and analyzed, less attention has been paid to another important characteristic of the process, that is, the reuse of the produced digestate to support and enhance the growth of new biomass [4]. The possibility of this reuse is extremely appealing as increasing attention is now paid to the need for nutrient recovery [5-7]. In particular, chemicals used as soil amendments may cause pollution through their incorrect disposal, and are also scarce in

\footnotetext{
* Corresponding author.

E-mail address: fabbrici@unina.it (M. Fabbricino).
}

relation to the amount required for agricultural purposes [8]. Thus, the reuse of digestate to improve the growth of fresh biomass, which in turn is used for biogas generation through anaerobic digestion, represents a virtuous cycle that includes energy production and nutrient recovery.

The aim of this paper is to verify the possibility of applying this cycle, using Vetiveria zizanoides as the biomass source. Many different reasons contribute to the choice of this particular species. First, Vetiveria zizanoides is characterized by very fast growth $[9,10]$; therefore, it is particularly advantageous as a renewable feedstock for energy production. Moreover, it is a perennial grass and grows in almost all types of soils at varying pH values (from 3.3 to 12.5), although sandy loamy soils are usually considered the most appropriate for maximum productivity [11]. This grass is resistant to pests, fire, and extreme climatic variations (e.g., severe frost, prolonged drought, flood, or submergence) [12]. Finally, it is also tolerant to many heavy metals, including $\mathrm{As}, \mathrm{Cd}, \mathrm{Pb}$, and $\mathrm{Zn}$ $[9,10,13]$, and it is able to efficiently absorb nutrients from the soil.

To verify the convenience of using Vetiveria zizanoides for biogas production through anaerobic digestion, first it was necessary to analyze and compare its biomethanation potential, both in the presence and absence of pretreatments, with that of a common garden grass. Grasses have an elevated lignin content which is generally considered poorly biodegradable [14], and it is therefore 